\title{
THE EFFECT OF ALTERATION OF TEMPERATURE UPON THE CATIONIC COMPOSITION IN PERENNIAL RYEGRASS ${ }^{1}$ )
}

\author{
W. DIJKSHOORN and M. L. 'T HART 2) \\ Central Institute for Agricultural Research, Wageningen
}

\begin{abstract}
SUMMARY
The present article discusses the results of two pot experiments on the effect of temperature and temperature changes on the mineral composition of perennial ryegrass.

In the first experiment (1955) the composition was studied of the re-growth of cut plants which had grown eight, sixteen or twenty-four days at approximately $10^{\circ}, 15^{\circ}$ or $20^{\circ}$ mean 24-hour temperature and in all combinations of these three temperatures, distributed over 8-day periods.

In the second experiment (1956) the effect was studied of a transition from $10^{\circ}$ to $20^{\circ}$ and from $20^{\circ}$ to $10^{\circ} \mathrm{C}$ on the mineral composition examined as a function of the time after the change of temperature.

It was found that a transition from cold to warm usually led to an increase in the cation content of the plants. As the effect caused the greatest changes in the potassium content, this also meant an increase in the value of the formulas $\mathrm{K}-\mathrm{Ca}-\mathrm{Mg}, \mathrm{K} / \mathrm{Ca}$, etc., which are commonly employed in investigations into the incidence of grass tetany in cattle in order to indicate the preponderance of potassium in the cationic composition.

A transition from warm to cold led to a reduction in the potassium contents and the values for the formulas of the potassium fraction in the cationic composition. In addition, an increase following the transition from cold to warm was cancelled by a succeeding cold period.

The highest values of the potassium level in the plants transferred from $10^{\circ}$ to $20^{\circ}$ were encountered ten days after the change in temperature, after which a decrease was again observed during the subsequent days.

Plants transferred from $20^{\circ}$ to $10^{\circ}$ showed a continuous decrease in potassium level as time went on, as did also the plants which were kept at $10^{\circ}$ or $20^{\circ}$ during the whole period, the potassium level being indicated by the formulas showing the preponderance of potassium in the cationic composition.

Observations of the nitrogen, water and nitrate content of the grass yield were used for the purpose of giving a tentative interpretation of the observations. The transition from cold to warm was accompanied by an increase in the nitrate content of the plants, i.e. by an increase in the nitrate uptake. Potassium being the cation with the greatest mobility, it is the preponderating element in the increase of the cation uptake which probably results from the increased nitrate uptake.
\end{abstract}

\section{INTRODUCTORY}

'T HART and KEMP (1956) found a relationship between the temperature gradient and the incidence of grass tetany in grazing dairy cattle. They were able to infer from observations that higher temperatures have an inhibitive effect on the incidence of grass tetany and that under the conditions prevailing in the Netherlands there is scarcely any further occurence of grass tetany after the mean spring temperature per 24 hours has risen beyond approximately $14^{\circ} \mathrm{C}$. Should the temperature fall below this limit in the autumn the disease will recur. But daily variations below the level of approximately $14^{\circ} \mathrm{C}$ were found to have an effect, in addition to the level of temperture during

1) Received for publication December 1, 1956.

2) At present Professor at the Agricultural University, Wageningen. 
the season, since it was discovered that there was an increase in the number of cases about 5 days after a rise in temperature, whereas 5 days after a drop in temperature the number of cases was observed to have decreased.

The lower the level from which the rise in temperature occurred, the greater was the increase after such a rise.

In view of these observations the question was raised as to whether the effect of changes in temperature on the incidence of grass tetany might not also be accounted for by a change in the chemical composition of the grass consumed by the cattle. The data of KEMP and 'T HART (1957) showed that the cationic composition of the grass is closely correlated to the incidence of grass tetany.

In view of this we considered it important to investigate the effect of temperature on the mineral composition of pasture.

To this end two pot experiments were made, viz. in the spring of 1955 and the spring of 1956.

In these tests, which were carried out with perennial ryegrass, the mineral composition of the grass was examined grown at a higher or at a lower temperature, and an examination was also made of the effect of changes in temperature on this composition.

The results obtained agree with what was found by KEMP and 'T $\mathrm{H}_{\mathrm{ART}}$ (1957) during field observations of the effect of temperature on the mineral composition of the grass.

In the discussion particular attention is paid to the effect of a rising and falling temperature on the potassium content of the grass produced, and on the ratios in which this element is encountered with respect to the remaining cations.

\section{Methods}

The soil used for the pot experiments was taken from a meadow in which grass tetany had occurred. It was a clay soil having $5 \%$ organic matter.

Enamelled culture vessels were filled with $6.5 \mathrm{kgs}$ of air-dry soil (corresponding to $5.6 \mathrm{kgs}$ of dry soil) which had been previously mixed with water until the moisture content reached 40 per cent. It was known from another experiment on the effect of the soil moisture level on the yield and composition of perennial ryegrass that this soil moisture level corresponded to the optimum growth.

The water added contained in solution $280 \mathrm{mgs} \mathrm{N}$ in the form of ammonium nitrate and a mixture of potassium chloride and sodium chloride. In the 1955 experiment the composition of the chloride mixture was such that 100 parts there of corresponded to 40 parts of $\mathrm{K}_{2} \mathrm{O}$. In the 1956 experiment the mixture contained 20 per cent of $\mathrm{K}_{2} \mathrm{O}$, and thus had more sodium to the same amount of potassium. In both experiments potassium was added in a quantity of $470 \mathrm{mgs}$ of $\mathrm{K}_{2} \mathrm{O}$ per pot. Hence in the 1956 experiment there was a somewhat greater addition of sodium to the soil. The object of this was to increase the sodium level in the plants in the last test so that any possible temperature effect on the sodium content might be rather better reflected in the result. Since sodium is fairly readily absorbed by perennial ryegrass (Dijkshoorn, 1956) the sodium level observed in the plants used in the 1956 experiment was considerably 
higher. This measure did not, however, throw fresh light on the behaviour of sodium in these experiments.

A moderate amount of nitrogen and potassium was used as the experiments were of comparatively short duration, and moreover the plant material employed already contains a certain reserve of nutriment.

The plants used were gathered from an experimental field of perennial ryegrass (selected strain of the pasture type) in the second half of March when there was no longer frost. In the space of a few days a great number of living shoots were selected in a cool space and the culture vessels planted with them as rapidly and uniformly as possible. The plants were then kept in the shade for three days in a cool greenhouse, and subsequently cut off at a height of about $3 \mathrm{cms}$, above the soil and distributed over different parts of the greenhouse. This moment was thereafter regarded as the beginning of the experiment.

The greenhouse compartments used were kept as well as possible at the required temperature by means of heating, ventilation, or by the use of water screening on the roof. It was obviously difficult to prevent variations in temperature caused by varying weather conditions. At the end of the experiment the temperatures recorded gave an idea of the actual temperature gradient during the period in question.

The pots were daily brought up to the correct weight with demineralised water until the soil moisture content was $40 \%$. Since in the warm compartments the losses due to evaporation were greater, in this case the pots were brought up to the correct weight twice a day. The evaporation losses occurring in the various temperature treatments were constantly compared in order to prevent systematic differences in soil moisture content. At the end of the experiments it was found that despite these precautions the soil moisture content at the higher temperatures had been on an average some per cent lower. But a separate experiment on the effect of the soil moisture level on the yield and composition of the grass confirmed the impression that this slight difference could not possibly have been the cause of the phenomena described below.

The cylindrical culture vessels used had a diameter of $20 \mathrm{cms}$. and gave a dry matter yield of from 1 to 16 grams, depending on the temperature and time of growing. The grass produced was harvested by cutting off to the original height when the experiment began (3 cms. above the soil) and gave a dry matter yield of from 1 tot 16 grams, depending on the temperature and time of growing. The grass was immediately dried in an air current at $110^{\circ} \mathrm{C}$. The samples were then transferred to a drying oven of $105^{\circ} \mathrm{C}$ and weighed 16 to 24 hours later. Depending on the yield, two to twelve pots were sampled on each occassion and the mean yield determined in fresh and dry weight. After sampling the pots were removed, so that all observations relate to a first cut.

\section{The 1955 EXPERIMENT}

This experiment was begun on 24th March and comprised two series of pots, one of which was only given nitrogenous fertilization ( $\mathrm{N}$ series) and the other potassium as well as nitrogen (NK series).

The plants were distributed over three compartments of a greenhouse con- 
tinuously heated as nearly as possible at $10^{\circ}, 15^{\circ}$ and $20^{\circ} \mathrm{C}$. After the first 8 days of re-growth, hereinafter referred to as period $\mathrm{A}$, the grass-yield was collected of a number of pots, and some of the pots remaining in each compartment were transferred to the other compartments.

After the next eight days (period B) a second sampling was carried out and some of the pots which then remained were again transferred to a different temperature. After the next 8-day period, hereafter referred to as $\mathrm{C}$, the last pots were sampled.

Consequently this experiment provided material from different periods of re-growth, viz. eight days in the case of the sampling after period $A$, sixteen days after periods $\mathrm{A}$ and $\mathrm{B}$, and twenty-four days after periods $\mathrm{A}, \mathrm{B}$ and $\mathrm{C}$. All combinations of the three temperatures employed, distributed over the 8-day periods, are represented in the material of the temperature treatments. Thus there are three idifferent treatments of the 8-day old grass, nine of the 16-day old grass and twenty-seven of the 24-day old grass. The mineral composition of the dry matter produced was examined in the case of each temperature treatment in the three age-groups. In the case of the $\mathrm{N}$ and $\mathrm{NK}$ series the results are shown separately in table 1.

In table 1 and the text below the three temperatures are referred to as the intended temperatures $10^{\circ}, 15^{\circ}$ and $20^{\circ}$. Figure 1 shows the temperature gradient recorded for the three greenhouse compartments during the periods A, B and C. During period A the coldest compartment was considerably colder than was intended, while during period B several unusually warm days made it impossible to avoid excessive temperatures.

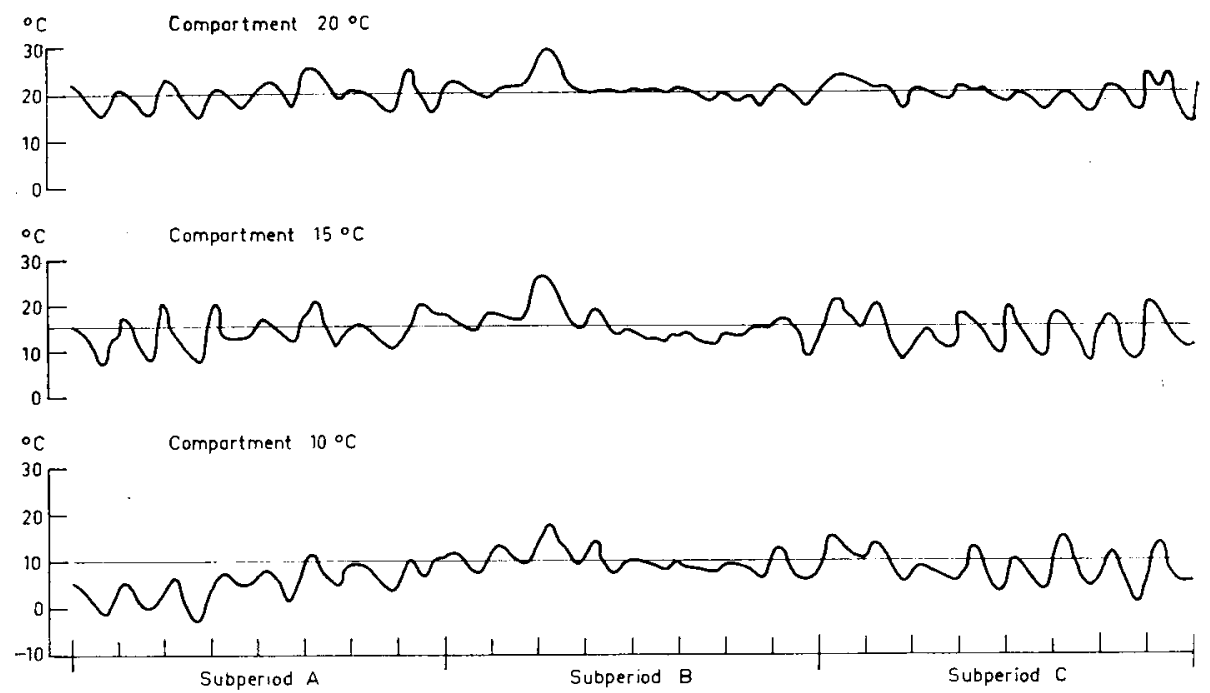

Fig. 1 Thermograph ReCORDINGS IN THE COMPARTMENTS USED IN THE 1955 EXPERIMENT during the sub-periods A, B and C, Each of 8 days duration.

\section{Discussion}

Since the composition of the grass yield may be affected by both the age of the grass and the character of the temperature gradient, this experiment was carried in the manner indicated above. In this way samples were obtained 


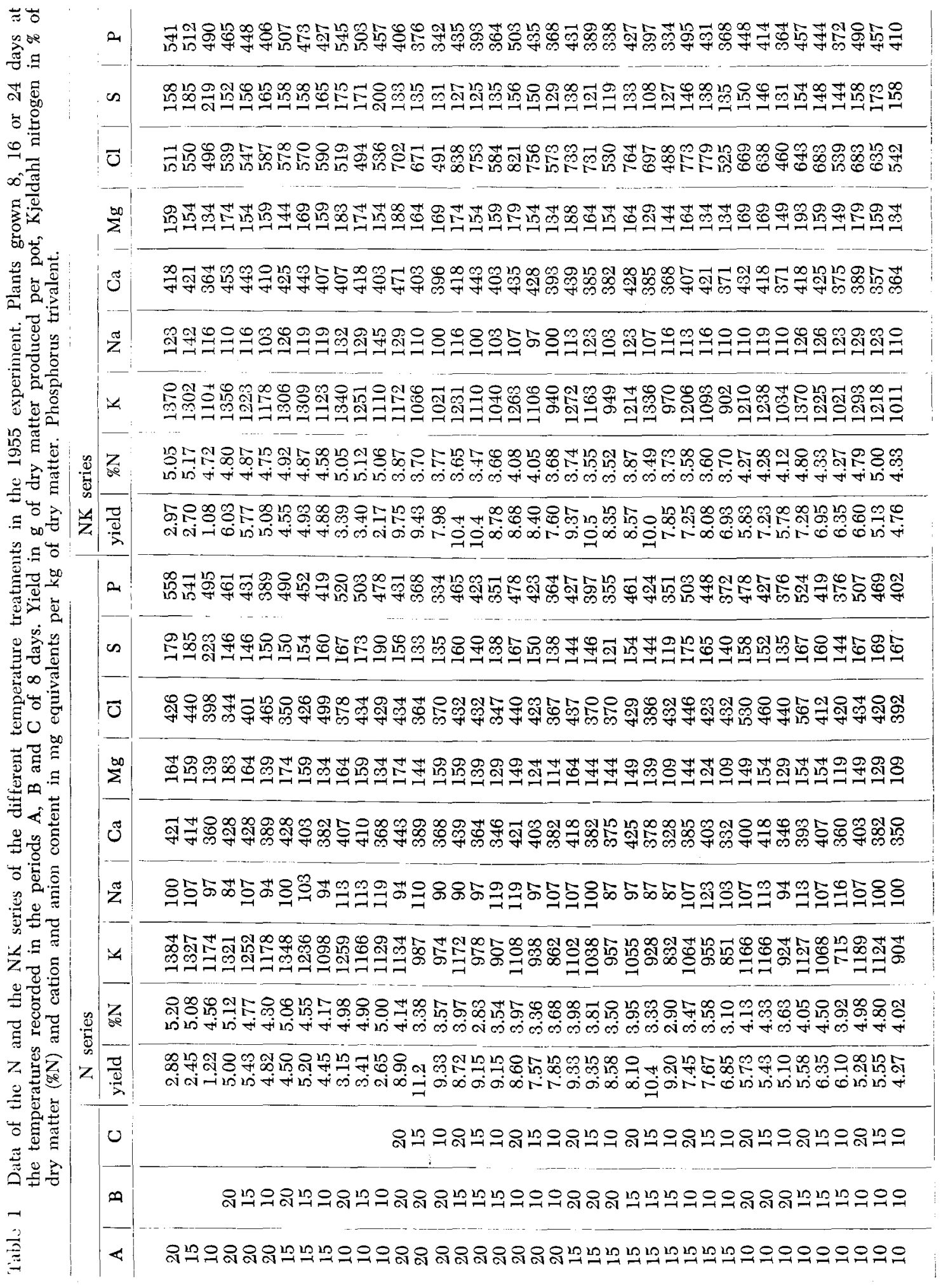


which belonged to different periods of growth and had grown at both a higher or lower temperature and with a different distribution of these temperatures over the various periods of longer growth. Despite the difficulty of maintaining the intended temperatures, by comparing the composition of these samples it is possible to show, for example, how the composition of the grass after a change in temperature from cold to warm is related to the composition found after a transition from warm to cold. It is probable that the results obtained will not differ substantially from those derived from an experiment in which the required temperatures have been better maintained.. For this reason reference is always made hereinafter to the temperatures $10^{\circ}, 15^{\circ}$ and $20^{\circ} \mathrm{C}$.

Since the present investigation into the cause of grass tetany in cattle is particularly directed to the cationic composition of the grass, and this group of components showed the most typical reaction to the temperature treatment, we confine ourselves chiefly to a discussion of the cation content observed in the various samples, and using these observations we shall attempt to discover some guiding factors for the effect of age and changes in temperature from cold to warm and vice versa on the cationic composition of the grass yield.

The observations carried out on the $\mathrm{N}$ and NK series showed a similar picture of reaction to the temperature. Although the cation contents in the NK series were higher, a study of the combined data leads to the same results as a study of each series separately.

Table 2 shows the mean total of the observations in the case of the 24-day old plants which had stood at one of the three temperatures during the periods $\mathrm{A}, \mathrm{B}$ and $\mathrm{C}$. Thus these averages include all observations for the cases shown, disregarding the temperature of the two periods not shown.

Table 2 Mean of the cation and nitrogen content observed in the plants of the $\mathrm{N}$ and the NK series after 24 days of re-growth in the 1955 experiment at different temperatures in the first (A), the second (B) and the third (C) subperiod of 8 days. At the bottom of the table the probability level (according to the $\mathrm{F}$ test) of the temperature effect in each subperiod is recorded. A dash denotes $\mathrm{P}>0.10$.

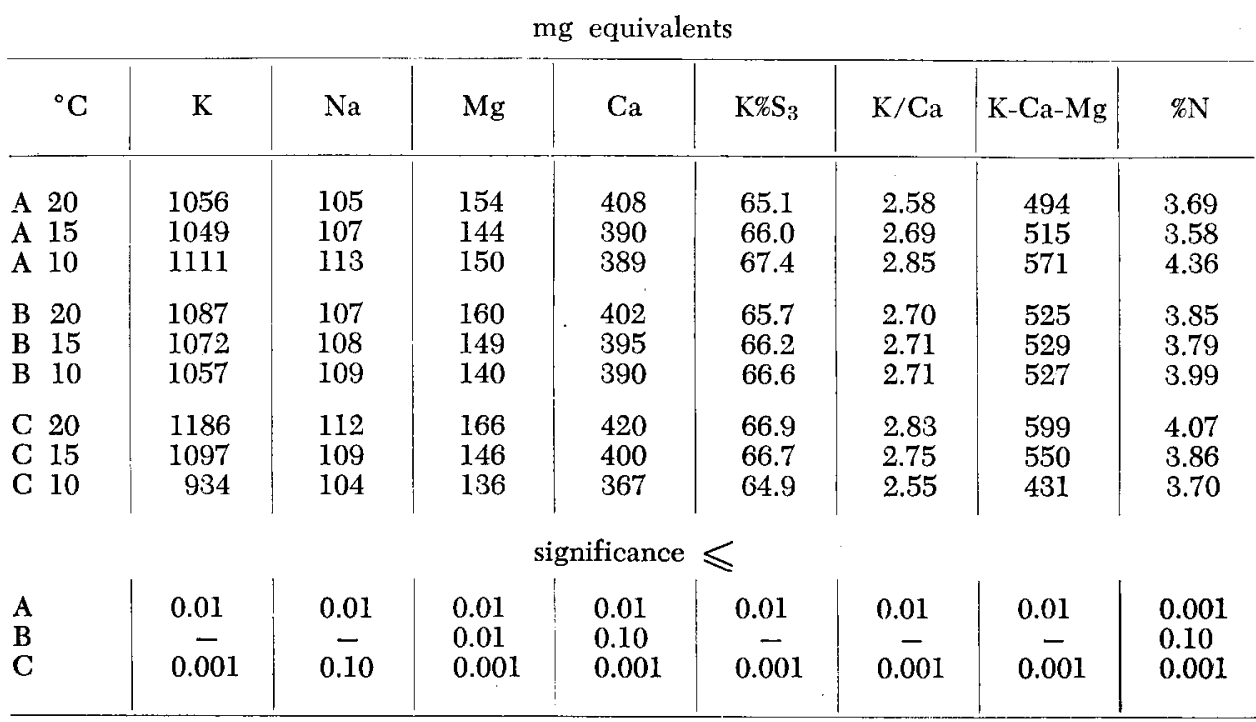


A statistical treatment of this data showed that the temperature of the first (A) and the last (C) eight days of the period of growth has a significant effect on the composition of the grass. The temperature of the second period B was not found to have any significant effect on the composition, with a single exception in the case of magnesium.

Since, as will be shown later, the temperature of the $\mathrm{B}$ period had a marked effect on the composition of the 16-day old grass, B thus representing the second half of the growth period, it follows that the temperature in $\mathrm{C}$ during the continued growth mainly cancelled the effect of the temperature during the middle period $\mathrm{B}$.

It might be expected that in the same way the effect of the temperature during the first eight days would be cancelled by the temperature effects of the subsequent periods. The fact that there is a well-marked temperature effect in period A must be attributed to the excessively low temperatures of the coldest group which at the beginning scarcely rose beyond $5^{\circ} \mathrm{C}$ and did not reach the required level of $10^{\circ}$ until the last part of the period (cf. fig. 1).

With respect to the character of the temperature effect, it can already be inferred from table 2 that a higher temperature during the first part of the growth period reduced the potassium content, and on the other hand a higher temperature during the last period gave rise to higher potassium contents. Higher magnesium and calcium contents were observed at the higher temperatures which occurred both in period $\mathrm{A}$ and period $\mathrm{B}$.

Although the differences found for the remaining cations are not less as compared to the mean content, and, as will be shown below, may even increase to 30 per cent, the effect found on the potassium content is numerically superior. As a result the values of the formulas actually employed in the pasture investigation in order to indicate the proportion of potassium in the cationic composition usually show the same gradient.

Table 2 shows the values of a number of conventional formulars. The formula $\mathrm{K}_{\%} \mathrm{~S}_{3}$ represents the potassium content in percentages of the sum of $\mathrm{K}+\mathrm{Ca}+\mathrm{Mg}$, and the remaining formulas are self-explanatory. This data also shows that higher values occur according as the temperature during the first period was lower and that of the last period higher. Further examination of the value of the potassium formulas shows that the differences in the transition from $10^{\circ}$ to $15^{\circ}$ are greater than in the transition from $15^{\circ}$ to $20^{\circ}$. In the case of period A this may be a result of the fact that the lowest temperature was too low, so that the temperature interval was greater than corresponds to the interval $10^{\circ}-15^{\circ}$. In period $\mathrm{C}$, however, in which, to judge from the temperatures recorded, there is a somewhat better approximation to the temperatures intended, the lowest temperature is likewise found to have a greater effect.

As was observed above, a similar temperature effect was noted in the case of both series $\mathrm{N}$ and series NK. Working out the combined data of the two series gives a result which agrees qualitatively with the results obtained by working out each series separately. But the use of the potassium and sodium chloride mixture had a noticeable effect on the mineral composition of the grass yield. The character of this effect may be summarised by means of the mean contents for all temperature treatments in the $\mathrm{N}$ and NK series separately. 
Table 3 Mean cation, anion and nitrogen content in the plants of the $N$ and the NK series after 24 days of re-growth in the 1955 experiment. Data recorded in $\mathrm{mg}$ equivalents per $\mathrm{kg}$ of dry matter, nitrogen monovalent, phosphorus trivalent. Significance of the difference between $\mathrm{NK}$ and $\mathrm{N}$ according to $\mathrm{F}$ test.

\begin{tabular}{|c|c|c|c|c|}
\hline & NK series & $\mathrm{N}$ series & Difference & $\begin{array}{l}\text { Significance } \\
\mathrm{P} \leqslant\end{array}$ \\
\hline \multicolumn{5}{|c|}{ cations } \\
\hline 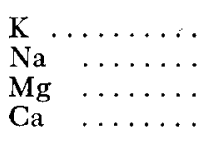 & $\begin{array}{r}1136 \\
113 \\
160 \\
405\end{array}$ & $\begin{array}{r}1009 \\
103 \\
139 \\
387\end{array}$ & $\begin{array}{l}+127 \\
+\quad 10 \\
+\quad 21 \\
+\quad 18\end{array}$ & $\begin{array}{l}0.001 \\
0.001 \\
0.001 \\
0.001\end{array}$ \\
\hline Total ...... & 1816 & $\begin{array}{c}1637 \\
\text { anions }\end{array}$ & +179 & 0.001 \\
\hline $\begin{array}{l}\mathrm{Cl} \ldots \ldots \ldots \\
\mathrm{P} \\
\mathrm{S}\end{array} \ldots \ldots \ldots \ldots$ & $\begin{array}{l}656 \\
411 \\
139\end{array}$ & $\begin{array}{l}423 \\
420 \\
150\end{array}$ & $\begin{array}{l}+233 \\
-\quad 9 \\
-\quad 11\end{array}$ & $\begin{array}{l}0.001 \\
0.05 \\
0.001\end{array}$ \\
\hline $\begin{array}{l}\text { Total } \ldots \ldots \ldots \\
\mathbf{N} \ldots \ldots \ldots\end{array}$ & $\begin{array}{l}1205 \\
2830\end{array}$ & $\begin{array}{r}992 \\
2710\end{array}$ & $\begin{array}{l}+213 \\
+120\end{array}$ & $\begin{array}{l}0.001 \\
0.05\end{array}$ \\
\hline
\end{tabular}

These are shown in table 3 . The differences are given a positive symbol when the mean in the NK series is higher. Fertilizing with the chloride mixture increased the potassium and sodium content. At the same time it is found that the calcium and magnesium content increased. As chloride is readily absorbed, the chlorine content in the plants belonging to the NK series is also considerably higher. In accordance with the previously found effect of chloride (DijksHoORN, 1955) the increase in the chlorine content is accompanied by a reduction in the sulphur and phosphorus contents, but a considerable increase is effected in the total anion content. In addition the mean nitrogen content in the NK series is found to be higher. Since all cation contents are higher in the NK series, in the case of the cations we have no indication of any antagonistic effect of the potassium used. On the other hand the chloride used has a distinctly antagonistic effect in the case of the anions. The antagonism might be conceived as a mechanism against an excessive uptake of either the cations or the anions. Regarded in this light an excessive uptake of anions would be be resisted by the plants of the NK series to a greater extent than a similar uptake of cations. It will therefore be neccessary to relate the increased total cation level in the plants of the $\mathrm{NK}$ series to the increased anion uptake resulting from the extra addition of chloride. It is understandable that this increase in the cation level is chiefly manifested in an increase in potassium which is readily taken up and is moreover added during fertilization. Thus the effect of the use of the mixture of potassium and sodium chloride on the cation level in the plants of the NK series cannot be interpreted independently of the anion uptake.

By making use of the mean contents found in the 24-day old grass it was possible to establish that the potassium level in the plants was higher according as they had been subjected to a lower temperature at the commencement of re-growth and a higher temperature upon the completion of re-growth. Despite shortcomings in the maintenance of the temperatures intended it is possible 
to accept the general conclusion that the potassium level is increased by a transition in the order cold-warm, as compared to a treatment in the order warm-cold. Moreover, since the temperature has no marked effect in the middle period, but does, in fact, have a marked effect on the composition of the 16-day old grass, it follows that the increase which succeeds the coldwarm treatment is cancelled by a subsequent cold period. In the same way, the effect of a warm-cold treatment is nullified by a subsequent warm period. That the effect of the first period still remains noticeable is to be connected with the excessively low temperature and also indicates that more intense cold at the beginning heightens the effect of a higher temperature at the end of the period of growth.

In connection with the above, i.e. the treatments in which the temperature is the same in the first (A) and last (C) period and varied in the middle (B) period, the results are consequently less illustrative in the case of the 24-day old grass. The effect of the previous change in temperature is mainly cancelled again during the last eight days in which the plants remained at the same temperature as that to which they had been exposed during the first period.

In this age-group the effect of a change in temperature is therefore more readily demonstrated in those cases in which only one change was made. We can also distinguish those cases in which the plants were exposed to the highest of the two temperatures for either $1 / 3$ of the time or for $2 / 3$ of the time, and these may be subdivided intro treatments in the order cold - warm and warm - cold. These treatments may be supplemented by cases $0 / 3$ and $3 / 3$, the former always being maintained at the lowest temperature and the latter always at the highest temperature.

In fig. 2 the potassium, calcium and magnesium contents observed for these cases are plotted in this way for the temperature transitions $10-20,10-15$ and 15-20. Plots with the left half blackened relate to the order warm-cold, those with the right half black to the order cold-warm, the solid circles to heat only, an the open circles to cold only. The plots of the NK series are connected by a pecked line, those of the $\mathrm{N}$ series by a full line.

In the temperature combinations $10-20$ and $10-15$ it is found that the potassium content in the plants which had been initially exposed to heat during $1 / 3$ of the period of growth is lower than that of plants which stood continually at $10^{\circ}$. The temperature being too low at the beginning of the experiment, the $10^{\circ}$ plants actually underwent a gradual rise in temperature, so that in effect they were subjected to a treatment of the cold-warm type. It will be shown below, however, that plants which underwent the transition from $20^{\circ}$ to $10^{\circ}$ may actually have a lower potassium content than plants continuously kept at $10^{\circ}$.

At the temperatures of $10^{\circ}$ and $20^{\circ}$ the highest potassium contents are found in the order cold-warm, the plants having stood at $20^{\circ}$ for $1 / 3$ of the period of growth, i.e. the last part, and these contents are not only considerably higher than those of the $10^{\circ}$ plants but also reached a higher level than the plants continually kept at $20^{\circ}$. When the warm period in the last part is extended to $2 / 3$ of growth the increase in the potassium content is smaller as compared to the $20^{\circ}$ plants. The graph for the temperature combination 
Fig 2 Cation contents in MG equivaLENTS PER KG OF DRY MATTER OF THE PLANTS WITH A 24-DAY REGROWTH IN THE 1955 EXPERIMENT, PLOTTED AGAINST THE FRACTION OF THE TIME DURING WHICH THE PLANTS WERE KEPT AT THE HIGHEST OF THE TWO TEMPERATURES.

Left-hand graphs: $10^{\circ}$ and $20^{\circ} \mathrm{C}$; middle graphs: $10^{\circ}$ and $15^{\circ} \mathrm{C}$; right-hand graphs : $15^{\circ}$ and $20^{\circ} \mathrm{C}$. Dots with the right half solid relate to the order cold-warm and with the left half solid to the order warm-cold. Open dots: constantly cold. Solid dots : constantly warm.
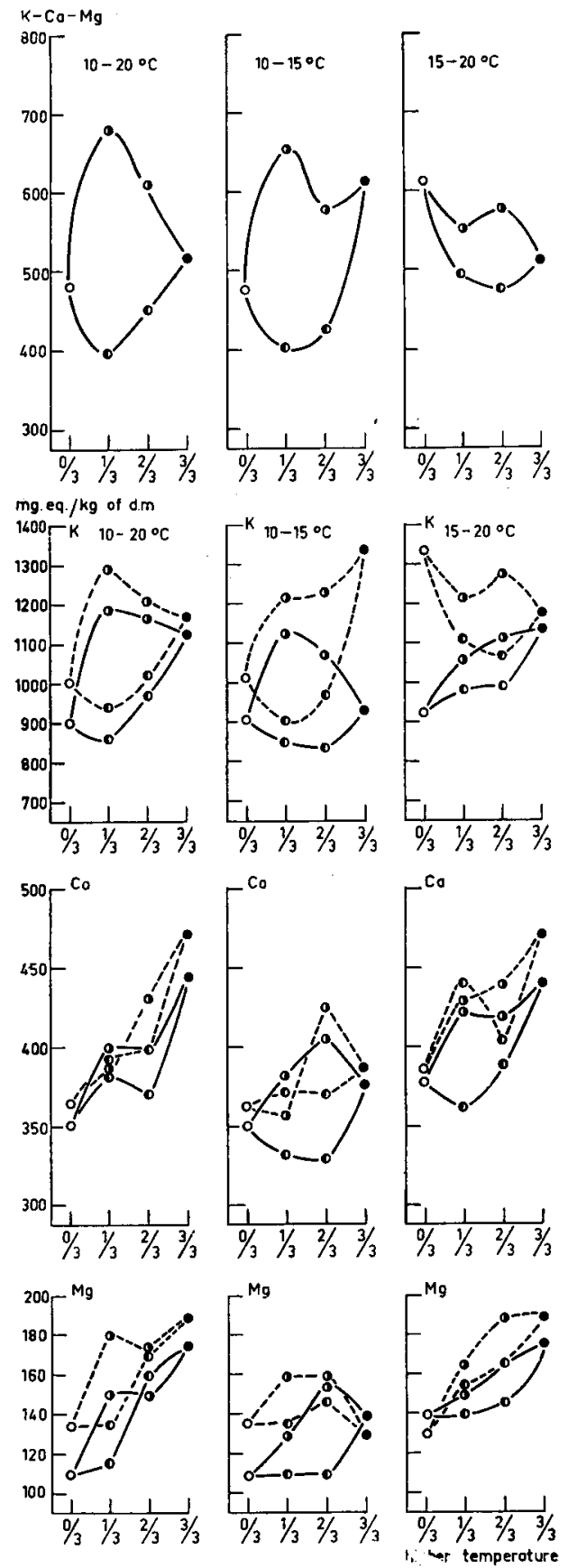

$10^{\circ}-15^{\circ}$ shows a comparable picture. In the NK series, however, the content of the $15^{\circ}$ plants is abnormally high, and this disturbs the regularity of the graph. The same observation distorts the graph for the temperature combination $15^{\circ}-20^{\circ}$. The rule that the order cold-warm leads to a higher potassium content in the plants also applies to the transitions from $15^{\circ}$ to $20^{\circ}$. But the 
effect is considerably smaller than was found in the case of the temperature transition $10^{\circ}-15^{\circ}$.

The various temperature transitions are found to have similar effects on the calcium and magnesium contents. Although on a percentage basis the changes in content are not inferior to those which occur in the case of potassium, they are considerably smaller numerically. As a result the graphs showing the values of the formula $\mathrm{K}-\mathrm{Ca}-\mathrm{Mg}$ are very similar to the graphs for the potassium content. Other formulas showing the proportion of potassium in the cationic composition have a corresponding gradient.

It follows from these observations made on the 24-day old plants that a transition from cold to warm, particularly when it occurs below $15^{\circ} \mathrm{C}$, causes the plants to have considerably higher potassium levels than does a transition from warm to cold. The highest values occur when the last eight days are warm ones. When the last warm period is one of 16 days the effect is reduced. This in itself indicates that the greatest effect on the transition from cold to warm occurs in less than 16 days.

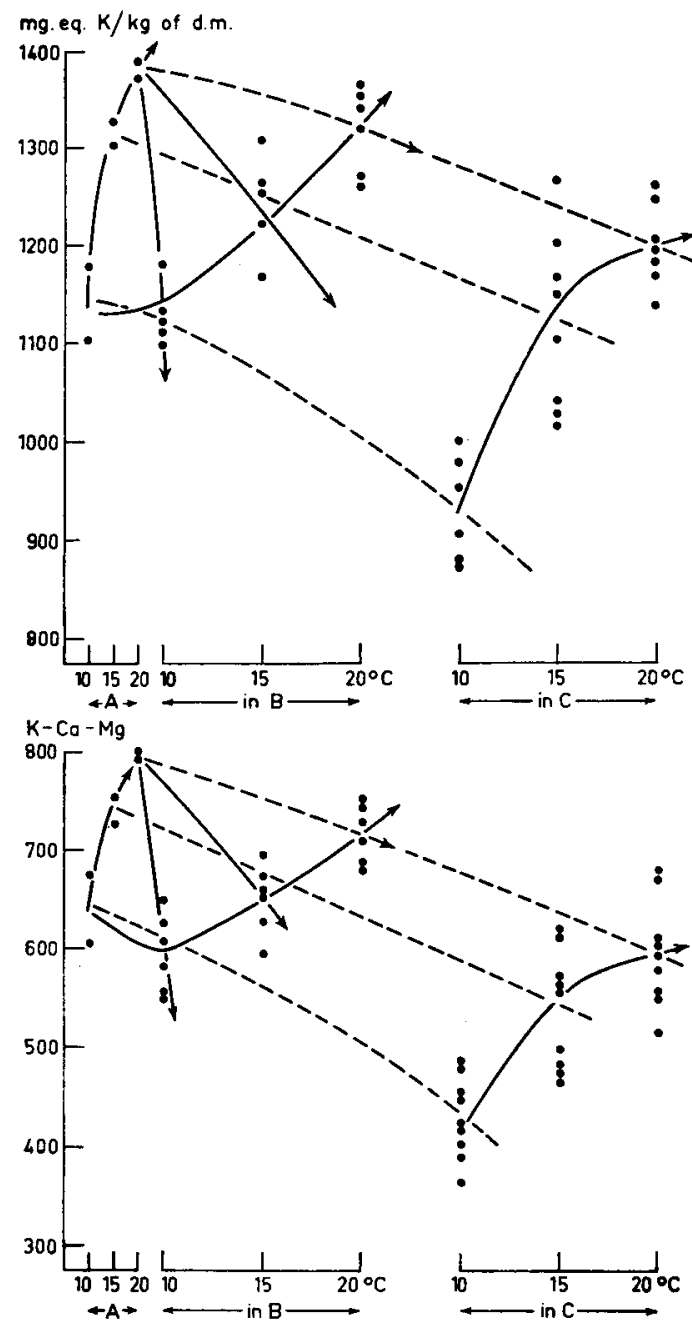

Fig, 3 Semi-diagrammatical REPRESENTATION OF POTASSIUM CONTENT AND K-Ca-Mg IN THE DRY MATTER PRODUCED AFTER PERIOD A, AFTER PERIODS A AND B, AND AFTER PERIODS A, B AND C, I.E. AFTER 8,16 AND 24 DAYS OF RE-GRoWTH. THE DATA ARE PLOTTED AGAINST THE TEMPERATURE DURING THE LAST 8 DAYS OF REGROW'TH. 
The potassium levels observed in the groups having varying periods of growth are summarised in the semi-diagrammatical graph in fig. 3. The absciss shows three temperature divisions. Above A are plotted the contents observed at the end of period A, i.e. in the 8-day old grass, at the corresponding temperatures. Above $B$ are plotted the readings taken from the 16-day old grass above the temperature the plants were exposed to during period $\mathrm{B}$. In the same way, the readings above $\mathrm{C}$ are derived from the 24 -day old grass which stood at the temperature indicated during period $C$. The latter data are the mean values for the $\mathrm{N}$ and $\mathrm{NK}$ series. The top graph relates to the potassium content, while the bottom one shows the values for the formula $\mathrm{K}-\mathrm{Ca}-\mathrm{Mg}$.

The higher the temperature, the higher is the potassium level of the 8-day old grass. The potassium level of the 16-day old grass depends to a high degree on the temperature in $\mathrm{B}$, i.e. the last eight days of growth. In the same way, the content in the 24-day old grass is mainly determined by the temperature of the last eight days, viz. period C. Hence, irrespective of the preceding treatment, the potassium level is chiefly determined by the temperature of the last 8-day period. Should this be higher a higher potassium level is observed in all age-groups.

The pecked lines show the decrease found during the ageing of plants which had stood at the same temperature. The result of this decrease is that the transition from $\mathrm{B} 10^{\circ}$ to $\mathrm{C} 20^{\circ}$, for example, shows a relatively slight effect, whereas the reverse case, the transition from $\mathrm{B} 20^{\circ}$ to $\mathrm{C} 10^{\circ}$ causes a considerable decline.

The overall picture suggested by the results of this experiment on the effect of temperature changes on the potassium level in grass may be described as follows. During re-growth at the same temperature the potassium level falls as time goes on. Superimposed on this decrease, temperature variations are reflected in a relative increase after a transition from warmer to colder. Hence the highest values occur after a rise of temperature in young grass, and the lowest values after a drop in temperature in older grass.

\section{THE 1956 EXPERIMENT}

In the preceding experiment the potassium level observed in grass belonging to the same period of re-growth after the transition from $10^{\circ}$ to $20^{\circ}$ was higher when this change had occurred eight days before than when the plants had been transferred 16 days before. When there is a more prolonged period of exposure to heat the increase brought about the transition is apparentently superseded by a decrease, and an optimum will occur at some point after a period which is less than sixteen days after the transition.

The 1956 experiment was arranged in such a way that it was possible to observe the course of the effect as time went on. Two temperatures were selected, viz. $10^{\circ}$ and $20^{\circ} \mathrm{C}$ mean temperature over a 24 -hour period, in view of the practical difficulties of maintaining small differences in temperature, and also in order to magnify the differences encountered. The actual temperature gradient during the experiment is shown in fig. 4. All plants were given the same moderate NK fertilization in the quantities shown in paragraph 2. 
The experiment was also begun on 24th March by distributing the cut plants over the two greenhouse compartments. After eleven days, i.e. on 4th April, a number of pots in each compartment were sampled in order to determine the yield and composition, and a number were transferred to the other compartment. Starting from this moment when a number of plants were placed in the other temperature, hereafter referred to as zero time, a sufficient number of pots of each treatment were sampled over a period of twenty days at intervals of 1,2 or 4 days to permit the determination of the composition and yield.

The experiment thus comprised four temperature treatments, - plants which had been kept during the whole period at $20^{\circ}(20-20)$ or $10^{\circ}(10-10)$, and

Table 4 Record of data of the different temperature treatments in the 1956 experiment. $t$ denotes the time of sampling in days after the transference of the plants of the $10-20$ and the $20-10$ treatments.

Yield in $\mathrm{g}$ of dry matter produced per pot, Kjeldahl nitrogen in $\%$ of dry matter (\%N) and cation and anion contents in $\mathrm{mg}$ equivalents per $\mathrm{kg}$ of dry matter. Phosphorus trivalent.

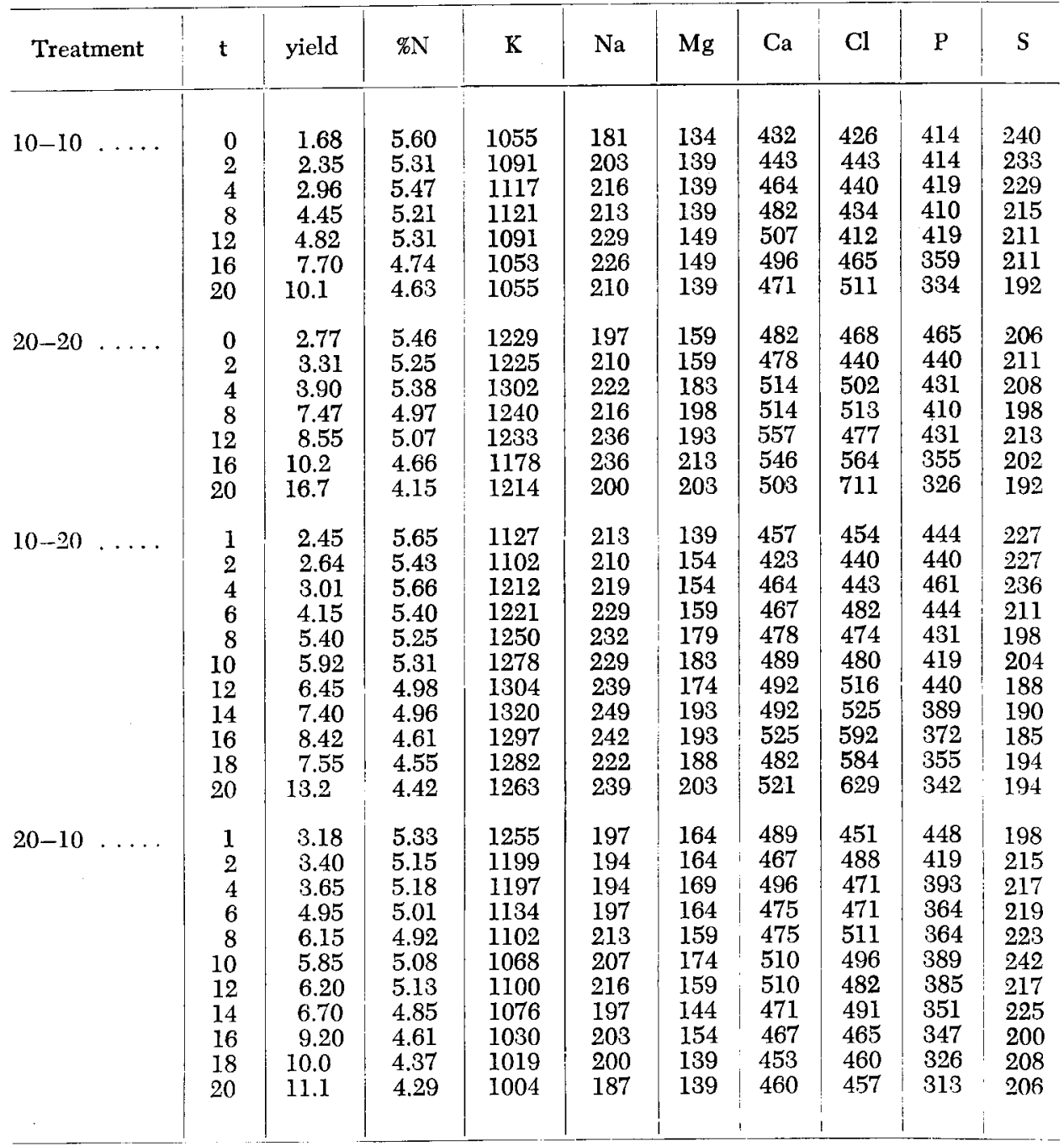



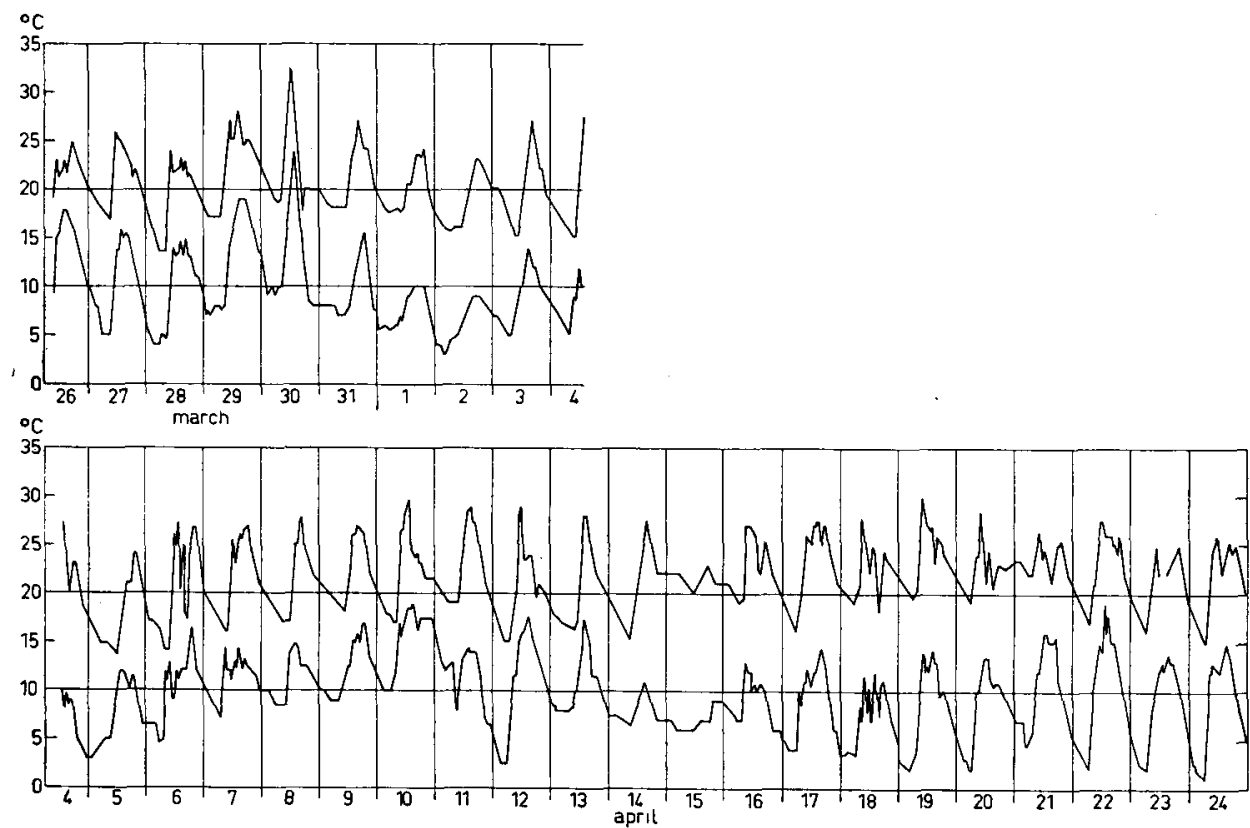

Fig. 4 ThERMOGRAPH RECORDINGS OF THE TWO COMPARTMENTS USED IN THE 1956 EXPERIMENT.

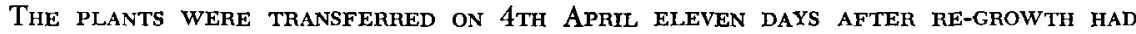
COMMENCED.

plants which after the first eleven days were transferred from $20^{\circ}$ to $10^{\circ}$ $(20-10)$ or from $10^{\circ}$ to $20^{\circ}(10-20)$. During and after the temperature change of the two-temperature treatment the composition of the plants was regularly determined at short intervals of a few days. The results are shown in table $\dot{4}$.

\section{Discussion}

The potassium, sodium, magnesium and calcium content of the plants belonging to the various treatments are plotted in fig. 5 against the time in days after the transfer of the plants belonging to the two-temperature treatments. The A graph relates to the plants which remained at $10^{\circ}$ for eleven of the preceding days and graph $\mathrm{B}$ to the plants derived from the $20^{\circ}$ greenhouse compartment.

At the time of being transferred the $20^{\circ}$ plants have a higher content in all cations than the plants derived from the $10^{\circ}$ compartment, and this difference persists when there is a continued residence time at the same temperatures. After the transfer from $20^{\circ}$ to $10^{\circ}$ the potassium content falls as time goes on. The contents of the remaining cations are then also lower than the contents found in the plants which remained at $20^{\circ}$.

The lower potassium content of the plants derived from the $10^{\circ}$ compartment shows a considerable increase during the first ten days after the plants have been transferred. Ten days after, when an optimum has been reached, this is again followed by a decrease.

The plants which remained at $10^{\circ}$ (treatment 10-10) also showed in the first instance a small increase in the potassium content. This is possibly due to an unavoidable increase in temperature in the $10^{\circ}$ compartment during this period 
resulting from weather conditions (cf. fig. 4). The differences between the effect of the 10-20 treatment and the 10-10 treatment are so marked, however, that this may be disregarded when drawing the further general conclusions.

Thus although the remaining cations react in a similar fashion in this case also, the potassium reaction preponderates to a very great extent. Correspond-

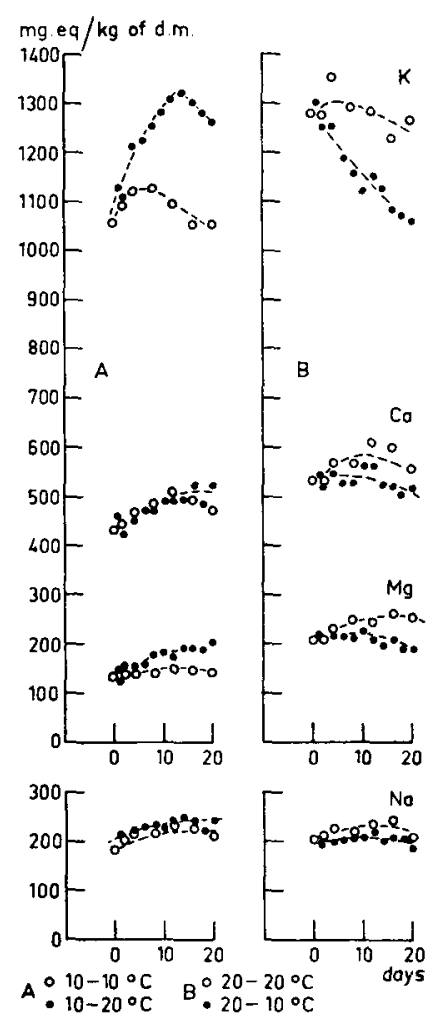

Fig. 5 Cation contents in MG EQUIVALENTS PER KG OF DRY MATTER PLOTTED AGAINST THE TIME AFTER TRANSFERRING THE PLANTS BELONGING TO THE TWO-TEMPERATURE TREATMENT (SOLID DOTS) IN THE 1956 EXPERIMENT. THE OPEN DOTS RELATE TO THE PLANTS KEPT AT THE SAME TEMPERATURE OF $10^{\circ}$ (A) OR $20^{\circ}$ (B).

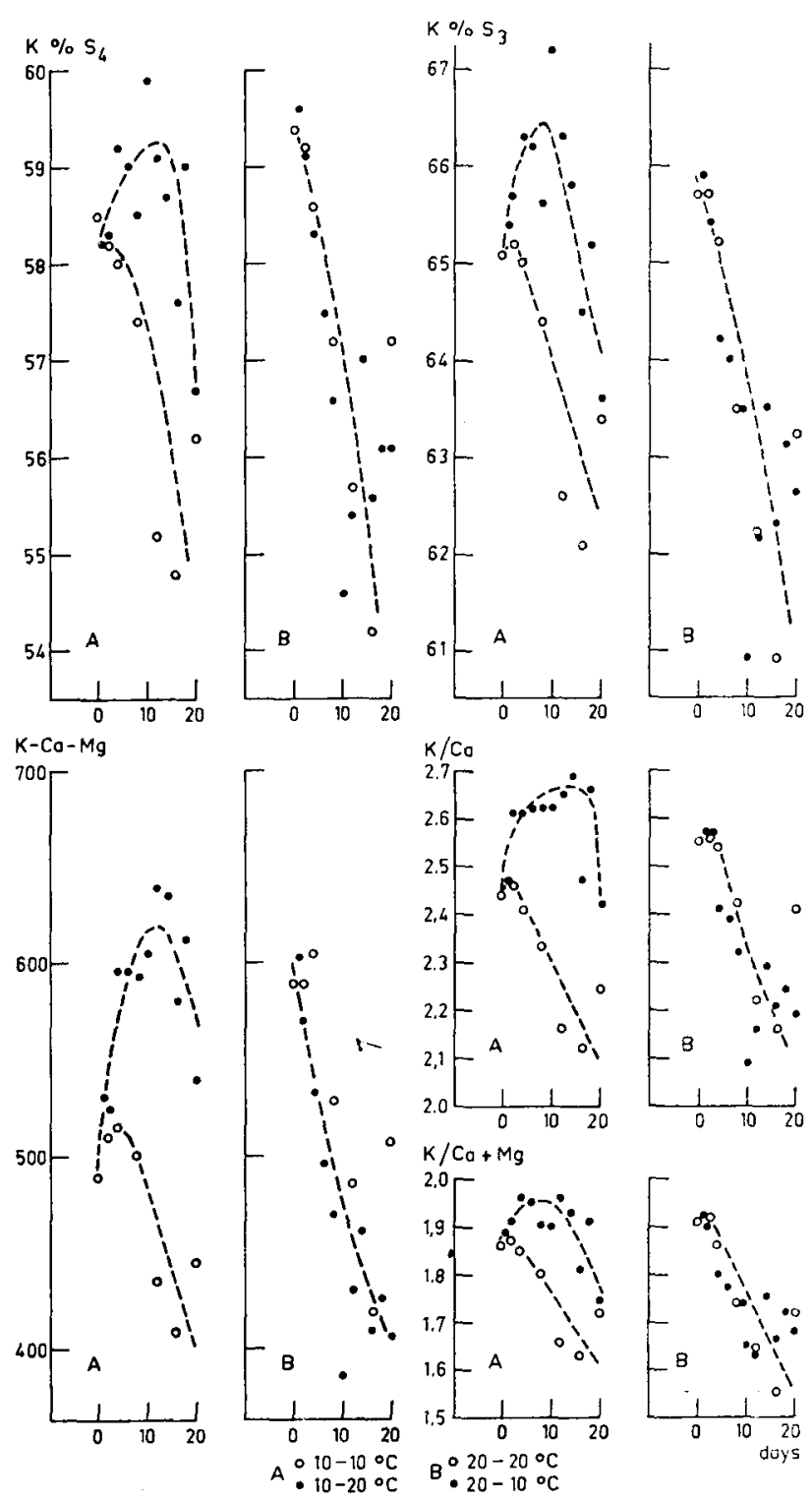

Fig. 6 Values OF THE Various potasstum formulas PLOTTED AGAINST THE TIME IN DAYS AFTER TRANSFERRING THE PLANTS BELONGING TO THE TWOTEMPERATURE TREATMENT IN THE 1956 EXPERIMENT. A graphs : 10-20 treatments (solid dots) and 10-10 treatments (open dots). B graphs : 20-10 treatments (solid dots) and 20-20 treatments (open dots). 
ing to the previous results, the transition from cold to warm leads to a considerable increase in the potassium content, and vice versa, the transition from warm to cold leads to a reduction of the potassium content. The greatest increase in the potassium content is observed ten days after the temperature transition.

Since the effect of the change of temperature is numerically much greater in the case of potassium than in the remaining cations, this may also be readily shown with the aid of the cation formulas used in the investigation into the incidence of grass tetany. To give an idea of the order of magnitude of these values, in fig. 6 a number of formulas are plotted against the time after the change of temperature. The formula $\mathrm{K}_{\mathrm{S}} \mathrm{S}_{4}$ represents the potassium content in percentages of the total cation content, and the other formulas are selfexplanatory. The 10-10 and 10-20 treatments are again included in the A graphs, and the $20-20$ and $20-10$ treatments in the $\mathrm{B}$ graphs.

Owing to the spread of the points nothing is to be gained by making a distinction between treatments $20-10$ and $20-20$. The decrease found in these cases as time went on is shown by a single dotted line. It is only possible to establish that both the transition from $20^{\circ}$ to $10^{\circ}$ and a continued residence time at $20^{\circ}$ show a decrease in the value of the potassium formulas as time goes on. Except for the small rise at the beginning, the $10^{\circ}$ plants show a decrease, as time goes on, for a continued residence time at $10^{\circ}$. After the transfer to $20^{\circ}$ there is a noticeable rise, the highest values being encountered some ten days after the change in temperature. In the last part of the period of observation a reduction as time goes on is also encountered in the 10-20 treatment. Owing to the high initial increase this reduction is at a higher level than the decrease observed in the $10^{\circ}$ plants.

At the time of the change in temperature both the values for the formulas and the potassium contents are higher in the plants which stood a $20^{\circ}$ during the preceding days than in the plants derived from the $10^{\circ}$ compartment. As in the case of the potassium content, about ten days after the transfer to $20^{\circ}$ the latter values reach a level approximately corresponding to that of the $20^{\circ}$ at the time of the temperature change. Since during this period the plants belonging to the 20-10 treatment show a decrease only the curves intersect, and at this moment the treatments have the same potassium level. In the case of potassium and the majority of the formulas, this moment occurs three days after the change in temperature, and at this moment the 10-20 and 20-10 treatments show the same potassium level. Thus during the first few days the 20-10 treatment shows a higher potassium level, whereas with the 10-20 treatment this is increasingly the case for more than three days after the temperature change up to ten days thereafter.

The 8-day period used in the 1955 experiment was therefore a favourable time for encountering considerably higher values for the transition from cold to warm. In it we also found an indication that sixteen days after the temperature change the differences will again be less. If this is so the reduction in the potassium level during the last ten days of the experiment should proceed more rapidly in the 10-20 treatment than in the 20-10 treatment. Although this cannot be inferred from figs. 5 and 6 arguments may be found to support the truth of this assumption. 
In fig. 7 we give a summary of the dry matter yield, the nitrogen content and the moisture content of the dry matter in the fresh material at the time of sampling. The absciss shows the time in days after the temperature change of the two-temperature treatments.

The plants which stood at $10^{\circ}$ during the preceding eleven days (10-10 and 10-20) show a lower yield and a higher nitrogen content at zero time. Continued growth at $20^{\circ}(20-20)$ causes higher yields, and the plants belonging to 20-10 also give a higher yield than those of the 10-10 treatment.

Moreover it should be observed that there is very little difference between the yields for the 10-20 and 20-10 treatments ten days after the change in temperature. Since this was the moment at which they showed the greatest

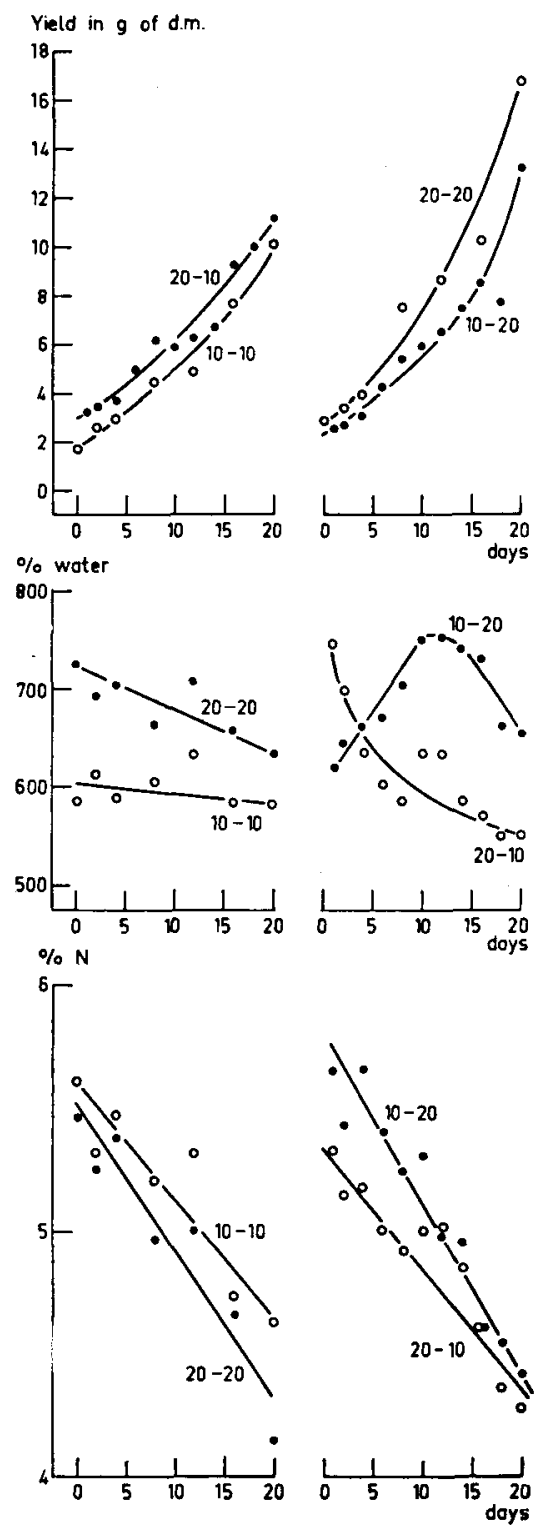

Fig. 7 Dry matter yield, water content and NITROGEN CONTENT IN PERCENTAGES OF THE DRY MatTER, PLOTted agaINST THE TIME IN DAYS AFTER TRANSFERRING THE PLANTS BELONGING TO THE 10-20 AND 20-10 TWOTEMPERATURE TREATMENTS IN THE 1956 EXPERIMENT. 
difference in cationic composition, the higher potassium level in the plants belonging to the 10-20 treatment cannot merely be due to a difference in the nutritional balance, but must be connected with a higher ,rate of uptake, dependent on the change in temperature.

With the aid of the data available it is possible to give a somewhat more complete discription o fthe physiological condition of the plants which accompanies this greater uptake.

In the bottom graph in fig. 7 the Kjeldahl nitrogen data of the various treatments are plotted against the time after the change in temperature. It is found that the plants belonging to the 10-20 treatments show a higher nitrogen content at zero time than those belonging to the 20-10 treatment. During the succeeding days the nitrogen content of the 10-20 plants falls more rapidly than that of the $20-10$ plants. Consequently the lines drawn through the points tend to converge.

In the single-temperature treatments (left-hand graph) the $20^{\circ}$ plants are initially again lower in nitrogen, whereas during the continued residence time at $20^{\circ}$ the rate at which the nitrogen content decreases is again greater than at $10^{\circ}$. The lines show a divergence, although it is less marked.

Generally speaking, younger grass also has a higher moisture content (loss in weight of the fresh sample at $105^{\circ}$ in percentages of the dry matter), and in the middle graph this is plotted against the time. The plots show that a higher moisture content occurs in the 20-20 plants than in the 10-10 plants, and moreover its decrease as time goes on is greater at $20^{\circ}$. A comparison with the nitrogen contents also shows that plants having the same nitrogen content have a higher moisture content in the 20-20 treatment than in the $10-10$ treatment.

The gradient of the moisture content in the plants belonging to the twotemperature (right-hand graph) is closely similar to the gradient of the potassium level. As regards the moisture content also, during the first few days the highest are found in the 20-10 treatment, after about three days 10-20 and 20-10 are equal, and thereafter the 10-20 treatment is higher and shows an optimum after about ten days. In this case, therefore, there is a substantially complete agreement with the potassium values $\mathrm{K}, \mathrm{K}-\mathrm{Ca}-\mathrm{Mg}, \mathrm{K} \% \mathrm{~S}_{4}$, etc.

A comparison with the nitrogen contents shows that after the first three-day period of adaption the plants at $20^{\circ}(10-20)$ again have a higher moisture content, with respect to the same nitrogen content, than the plants at $10^{\circ} \mathrm{C}$ (20-10).

It appears an unlikely assumption that plants having the same Kjeldahl nitrogen content are in "equilibrium" with a lower moisture content at a lower temperature. Moreover, the adaption period of ten days after the transition from $10^{\circ}$ to $20^{\circ}$ is too long for this and rather points to metabolic changes. On studying the nitrate content it was found that when plotted against the time these values were in agreement with the gradient of the potassium and water levels in the plants belonging to the various temperature treatments. This in itself shows that the transition from cold to warm is followed by an increase in the rate of the nitrogen uptake. This is presumably accompanied by an increase in the metabolic activity, an increase in the moisture content of the plants, and a increase in the cation uptake. 
The increase in the cation uptake is probably a general tendency which is not necessarily chiefly reflected in potassium. The fact that numerically the greatest increase is found in the potassium level is to be explained by the great ease of uptake (DIJKSHOORN, 1955, 1956) and mobility of this cation in the plant (KEMP and DiJKshoorn, 1956). The obvious corollary is that when potassium is available in sufficient quantities this ion is in the first place capable of supplying the necessary equivalents at a sufficient rate. The discussion of the results has been mainly confined to the cations. It might be asked how the anions reacted to the treatments applied. The chloride anion in particular shows a great ease of uptake and mobility in perennial ryegrass.

In our view the fact that the gradient of the anions in the various treatments showed a much less characteristic response is connected with the fact that the behaviour of the cations is closely bound up with the nitrate response in the various treatments, whereas the behaviour of the anions is of a more supplementary kind. A parallel to such cases may be found in the relationships between the cation and anion uptake formulated by BEAR (1950), but any further discussion would be outside the scope of this article.

\section{ACKNOWLEDGEMENTS}

The authors wish to express their gratitude to Dr. W. B. DEYs, head of the chemical department, for his special care in the handling of the small samples for analysis and for valuable discussions. Their thanks are also due to Mr. C. A. Hoveyn and Mr. G. B. Staal, who performed a statistical treatment of the results.

\section{ReFERENCES}

BEAR, F. E. : Agronomy Journal 42 (1950) 176.

Dijkshoons, W. : Verslag C.I.L.O. over 1954 (1955) 233.

- - : Verslag C.I.L.O. over 1955 (1956) 187.

Hart, M. L. 'T and A. Kemp : Tijdschr. Diergeneeskunde 81 (1956) 84.

Kemp, A. and W. Dijkshoorn: Verslag C.I.L.O. over 1955 (1956) 100.

- - and M. L. 't Hart : Netherl. J. Agric. Sci. 5 (1957) 10. 